\title{
A TELEVISÃO COMO RECURSO PEDAGÓGICO NO PROCESSO DE
} ENSINO APRENDIZAGEM

\author{
Cristiane Pereira Peres* \\ Mariclei Przylepa** \\ Cleber José de Oliveira***
}

\begin{abstract}
RESUMO: $O$ artigo objetiva analisar o uso da televisão como recurso pedagógico no processo de ensino $e$ de aprendizagem. O referencial teórico metodológico teve como base a pesquisa bibliográfica. Problematiza-se o recurso da televisão como ferramenta pedagógica na educação escolar. Resultados evidenciaram que, apesar, desse recurso tecnológico contribuir na construção de novos conhecimentos, $e$ ser muito utilizado em sala de aula, necessita ser incorporado de modo crítico, reflexivo e qualitativo ao planejamento docente com intuito de se tornar uma estratégia de ensino no alcance dos objetivos propostos para o processo de ensino e de aprendizagem.
\end{abstract}

ABSTRACT: The article aims to analyze the use of television as a pedagogical resource in the teaching and learning process. The theoretical and methodological framework was based on bibliographic research. The use of television as a pedagogical tool in school education is problematized. Results showed that, despite this technological resource contributing to the construction of new knowledge, and being widely used in the classroom, it needs to be incorporated in a critical, reflective and qualitative way in the teaching planning in order to become a teaching strategy in the reach of the students. objectives proposed for the teaching and learning process.

PALAVRAS-CHAVE: Televisão. Planejamento. Ensino aprendizagem.

KEYWORDS: Television. Planning. Teaching and learning.

\section{INTRODUÇÃO}

O presente artigo aborda o uso do multimeio, a televisão, no processo de ensino e de aprendizagem, investigando esse recurso tecnológico como ferramenta pedagógica na sala de aula, visto que, as tecnologias envolvem um campo cada vez mais amplo e diversificado nas pesquisas realizadas, contribuindo com os estudos, a fim de proporcionar estratégias inovadoras no sistema educacional, promovendo com isso mudanças no paradigma tradicional de educação.

Segundo Castells (2016), no final do século XX, com a reestruturação do modo de produção capitalista, surge uma nova estrutura social, anunciada de várias formas pela diversidade cultural, ocorre um rearranjo dos mercados, o aumento da concorrência econômica global, o desenvolvimento de um novo modo de comunicação (informacional) e o crescimento das redes de computadores. Apresenta-se, uma nova ordem econômica e 
social, tendo como centralidade a revolução tecnológica focada na Tecnologia da Informação e da Comunicação (TIC).

Nessa direção, as tecnologias podem fornecer estratégias inovadoras para o desenvolvimento da educação brasileira. Assim, é importante investigar como o uso da televisão pode contribuir com a aprendizagem dos educandos, na perspectiva da formação da autonomia e da construção do conhecimento social e político, bem como, com sua interação e socialização no contexto tecnológico vigente. Como é assegurado pela Lei de Diretrizes e Bases da Educação (LDB) 9394/96 art. 32 inciso II, que a formação dos alunos do ensino fundamental deve ocorrer por meio da compreensão "do ambiente natural e social, do sistema político, da tecnologia, das artes e dos valores em que se fundamenta a sociedade" (BRASIL, 1996).

Assim, sob as novas perspectivas educacionais quanto ao uso da tecnologia como recurso didático, os docentes deparam-se com um novo contexto que exige novas posturas e metodologias, tanto do professor, quanto do aluno, que se encontram inseridos na contemporaneidade em um espaço tecnológico. Assim, em contextos atuais de aprendizagem, a partir das tecnologias educacionais, que configuram novas formas e espaços de produção do conhecimento, o professor passa a ser um mediador no processo de ensino e de aprendizagem, e não mais o detentor do saber e o centralizador do conhecimento.

Nesse contexto de inserção tecnológica, no processo de escolarização, é importante e necessário investir em formações continuadas para os docentes, contribuindo assim com a criação de novos ambientes de aprendizagem, que podem conduzir professores e alunos ao exercício de uma prática pedagógica capaz de reelaborar e reorganizar a aprendizagem em contextos críticos e reflexivos, de modo a contribuir com a formação integral dos alunos, no âmbito social (comunicativo e interativo) e intelectual (cognitivo e cultural).

Na contemporaneidade, a revolução tecnológica não é caracterizada pela centralidade do conhecimento e da informação, mas sim pela sua aplicabilidade para a produção de conhecimentos e de dispositivos de processamento/comunicação da informação, em um ciclo de realimentação acumulativo entre inovação e seu uso (CASTELLS, 2016).

Deste modo, as transformações ocorridas na sociedade contemporânea exigem dos sujeitos novas formas de acesso à informação e ao conhecimento, avivando o processo de ensino e de aprendizagem e a construção do conhecimento, mostrando, assim, a importância do uso das tecnologias na educação. Nesse contexto, as escolas necessitam de recursos midiáticos para interagir com a realidade dos discentes. Tais recursos podem oportunizar a obtenção do conhecimento historicamente construído pelos sujeitos e possibilitar um aprendizado em âmbito global, ou seja, educacional, político, linguístico e étnico. 
Portanto, a problemática apresentada consiste em como utilizar a televisão nas práticas pedagógicas de uma maneira significativa e não apenas como mais um recurso para entreter e/ou transmitir conteúdos. Nesse sentido, a pesquisa realizada buscou contribuir com os estudos epistemológicos acerca da apreensão dos recursos tecnológicos como instrumentos pedagógicos para o processo de ensino e de aprendizagem.

Para tanto, o texto encontra-se organizado em três seções. A primeira apresenta a relação entre as tecnologias e a educação; a segunda aborda as contribuições da televisão no processo educacional e, por fim, as considerações sobre a pesquisa realizada.

\section{TECNOLOGIAS E EDUCAÇÃO}

Ao final do século XX, diversas transformações sociais, tecnológicas, econômicas e culturais, se uniram para dar origem a uma nova forma de sociedade, a sociedade em rede, que se constituiu como um sistema global, anunciando uma nova forma de organização social. Nesse sentido, a principal característica espacial da sociedade em rede é a conexão em rede entre o local e o global (CASTELLS, 2016).

Entendendo que a sociedade se encontra cada vez mais propensa a se organizar em rede, acredita-se ser necessário apreender a função da rede no contexto societal. Para tanto, as considerações de Castells (2016) são profícuas e esclarecedoras ao anunciarem que as redes constituem a nova morfologia social de nossas sociedades e que a difusão da lógica de redes modifica, de forma fundamental, a operação, os resultados dos processos produtivos, as experiências, o poder e a cultura social. A partir dos dizeres do autor, seria o começo de uma nova existência, de uma nova era, a era da informação, referendada pela autonomia da cultura que origina as bases materiais de nossa existência.

Assim, é possível constatar que as tecnologias trouxeram mudanças culturais no modo de pensar e agir das pessoas, alteraram hábitos, costumes, o modo de produção de bens e serviços, as relações interpessoais no trabalho, no ambiente escolar e doméstico. A multimídia influencia a cultura social ao possibilitar um novo estilo de vida, "centralidade na casa" e "individualismo", captando em seu domínio a maioria das expressões culturais em toda a sua diversidade. Em que a cultura é mediada e determinada pela comunicação, as próprias culturas, isto é, nossos sistemas de crenças e códigos historicamente produzidos, são transformados de maneira fundamental pelo novo sistema.

Ressalta-se que os instrumentos tecnológicos são recursos existentes desde o surgimento da humanidade; logo, os instrumentos que foram inventados pela sociedade primitiva como meio de sobrevivência, as relações e a comunicação, também são considerados meios tecnológicos. Desse modo, 
Os multimeios são materiais em constante desenvolvimento. O progresso da tecnologia faz surgir os mais variados suportes, em diversos formatos, tornando quase impossível organizar uma relação completa de todos os tipos existentes. Sem apreensão da exaustividade, podem ser citados: álbum seriado, atlas, brinquedos, cartão-postal, cartaz (AMARAL, 1987, p. 46).

Nos dias atuais, a tecnologia, quando incorporada ao processo de ensino e de aprendizagem proporciona novas formas de ensinar e, principalmente, de aprender, pois o contexto social encontra-se em um momento no qual a cultura e os valores da sociedade estão mudando, o que exige novas formas de acesso ao conhecimento, assim como, a construção de saberes críticos, contextualizados e globalizados acerca da realidade socioeconômica, política e cultural. Logo, a escola precisa ter o compromisso de proporcionar aos alunos a apropriação dos saberes, procedimentos, atitudes e valores, com vistas a contribuir com a sua formação integral e, principalmente, com habilidades para interagir e interferir no contexto social e tecnológico em curso.

Sendo assim,

\begin{abstract}
A evolução tecnológica não se restringe apenas aos novos usos de determinados equipamentos e produtos. Ela altera comportamentos. A ampliação e a banalização do uso de determinada tecnologia impõem-se à cultura existente e transformam não apenas o comportamento individual, mas o de todo o grupo social. [...] As tecnologias transformam suas maneiras de pensar, sentir e agir. Mudam também suas formas de se comunicar e de adquirir conhecimentos (KENSKI, 2010, p. 21).
\end{abstract}

Cabe então, compreender o uso da televisão em sala de aula como um recurso mediador do conhecimento, possibilitando aos discentes momentos de interação, comunicação e socialização na construção de aprendizados e mudanças de comportamentos em âmbito individual e coletivo. Para tanto, deve-se valorizar o conhecimento que o discente já possui e construir outros ainda desconhecidos. Assim, a utilização da televisão em sala de aula exige dos educadores um planejamento reflexivo com a elaboração de objetivos críticos e contextualizados com as realidades sociais e culturais dos discentes, de modo a romper com o uso técnico desse recurso.

$\mathrm{Na}$ era das tecnologias digitais, a formação docente precisa ser contínua, de modo que seja possível atender as exigências presentes no processo de ensino e de aprendizagem em relação ao desenvolvimento de novas práticas pedagógicas digitais capazes de promover um ensino qualitativo e equitativo. O professor precisa realizar um monitoramento constante dos resultados alcançados, trabalhar de forma democrática, dinâmica e com o uso de recursos tecnológicos de modo a desenvolver aprendizagens e habilidades nos educandos para que possam utilizá-las em suas atividades diárias e educacionais. 
Ressalta-se que o ato de ensinar, quando incentivado pela formação continuada, proporciona estímulos na vida pessoal, profissional e social dos sujeitos envolvidos, suscitando, assim, um processo educativo mais significativo e prazeroso.

Assim,

A midiabilidade é um dos principais problemas a serem pensados pela escola [...]. Não se trata de tentar dissipar a influência da mídia na vida das pessoas, mas de explicitar este fenômeno e fornecer alguns pressupostos críticos, valorizando elementos culturais que muitas vezes o aluno já possui (NAPOLITANO, 2003, p. 12).

Os multimeios em sala de aula precisam ser selecionados como suporte para o professor em seu planejamento, não como um fim, mas sim, um meio de interconexão entre discentes, docentes e o que se pretende ensinar, inserindo a televisão na educação em uma proposta multidisciplinar e transdisciplinar de ensino e de aprendizagem.

Conforme Santos, a

[...] transdisciplinaridade diz respeito à dinâmica dos diferentes níveis de realidade. Para conhecê-la é preciso o conhecimento disciplinar, o que quer dizer que a própria pesquisa transdisciplinar se apoia na pesquisa disciplinar. No entanto, enfocada a partir da unidade do conhecimento. Portanto, conhecimentos disciplinares e transdisciplinares não são antagônicos, são complementares (2004, p. 111).

Com o uso da televisão é possível trabalhar o (re)conhecimento, o respeito e a valorização da diversidade étnica e cultural, por meio da seleção de filmes, documentários, desenhos e músicas, estabelecendo diálogos com as diversas culturas e com os diversos campos dos saberes. Deste modo, os recursos e as práticas pedagógicas utilizadas em sala de aula são decisivos para um ensino multidisciplinar e transdisciplinar, possibilitando aos alunos conhecer as diversas realidades sociais, étnicas e culturais e os diversos saberes.

Para Libâneo,

Os educadores são unânimes em reconhecer o impacto das atuais transformações econômicas, políticas, sociais e culturais na educação e no ensino, levando a uma reavaliação do papel da escola e dos professores. Entretanto, por mais que a escola básica seja afetada nas suas funções, na sua estrutura organizacional, nos seus conteúdos e métodos, ela mantém-se como uma instituição necessária à democratização da sociedade $(2011$, p. 9).

Portanto, as tecnologias digitais presentes na sociedade e na escola, como a televisão, permitem novas metodologias, novas abordagens, novas formas de agir, de se comunicar 
e compreender as diversas realidades sociais, desenvolvendo assim novas análises e aprendizados significativos e contextualizados.

\section{O USO DA TELEVISÃO NO PROCESSO DE ESCOLARIZAÇÃO E FORMAÇÃO DISCENTE}

As tecnologias digitais, cada vez mais têm ocupado espaço nas redes de ensino, não substituindo o professor em sala, mas são incorporadas como suporte nas metodologias docentes e deve contribuir com a participação, a interação, a criatividade e o interesse dos discentes no processo de ensino e de aprendizagem, assim como, com a formação docente. Perrenoud (2000, p. 125), afirma que a comunicação e as novas tecnologias da informação "[...] transformam espetacularmente não só a maneira de comunicação, mas também de trabalhar, de decidir, de pensar".

A televisão chegou ao Brasil na década de 1950, e é nos anos de 1990 que tem início sua contribuição na educação com as emissoras educativas, como: a TV Escola, TV Cultura, TV SESC e Futura. A TV Senado e TV Câmara possuem como abordagem o universo político.

Assim, o uso da televisão como recurso educacional possibilita novos olhares no fazer pedagógico, pois trabalha os conteúdos selecionados pelo docente de forma lúdica, e oportuniza uma maior participação dos alunos nas aulas e uma aproximação da realidade na qual estão inseridos, visto que os mesmos possuem interesses em recursos midiáticos e aprendem com mais facilidade por meio de instrumentos audiovisual.

A construção do conhecimento não pode ocorrer distante da realidade dos alunos, mas sim, relacionado com as diversas realidades sociais, econômicas, políticas, religiosas e étnicas. Só assim é possível contribuir com a formação de sujeitos democráticos e que terão em suas manifestações o respeito ao outro.

Nesse viés, a utilização das diversas tecnologias na educação, pode permitir "[...] ler criticamente o mundo dos meios de comunicação, mas, também, de promover as próprias formas de expressão [...], construindo espaços de cidadania pelo uso comunitário e participativo dos recursos da comunicação e da informação" (SOARES, 2011, p. 37).

Nesse caminhar, ante a inserção das tecnologias digitais na educação é necessário refletir sobre os usos das mesmas na formação acadêmica, pessoal e profissional dos discentes. Como alerta Pretto:

Não basta, portanto, introduzir na escola o vídeo, televisão, computador ou mesmo todos os recursos multimidiáticos para fazer uma nova educação. É necessário repensá-la em outros tempos, porque é evidente que a educação numa sociedade dos mass media, da comunicação generalizada, não pode prescindir 
da presença desses novos recursos. Porém, essa presença, por si só, não garante essa nova escola, essa nova educação (PRETTO, 1996, p. 112).

Os conteúdos a serem trabalhados usando os recursos tecnológicos devem perpassar o planejamento educativo, uma vez que os aparelhos por si só não contribuem com o desenvolvimento qualitativo da educação e nem instigam o interesse dos alunos. Os encaminhamentos dados, pelos educadores respaldados em seus objetivos de ensino, com o uso das tecnologias, é que potenciam as práticas de aprendizagem as quais podem ser emancipadoras e democráticas.

Nesse sentido, "[...] o poder e a influência da TV só podem ser revertidos em conhecimento escolar, na medida em que o uso da TV em sala de aula, seja a consequência de um conjunto de atividades e reflexões compartilhadas" (NAPOLITANO, 2003, p. 25) e mediadas pelo docente a partir dos conteúdos selecionados que fazem referências à realidade socioeconômica e cultural dos discentes.

A linguagem audiovisual aproxima e insere os alunos em uma diversidade de informações, que mediadas pelo professor, geram novos conhecimentos. Os recursos audiovisuais aproximam os alunos da sua realidade, possibilitando assim novas leituras e ações em sociedade. Nesse sentido, a televisão, ao estar inserida de modo contextualizado, dinâmico, crítico e cultural no planejamento docente, desenvolve a aprendizagem e a formação dos discentes em âmbito escolar, pessoal, social e cultural.

Salienta Perrenoud que
As novas tecnologias podem reforçar a contribuição dos trabalhos pedagógicos e didáticos contemporâneos, pois permitem que sejam criadas situações de aprendizagem ricas, complexas, diversificadas, por meio de uma divisão de trabalho que não faz mais com que todo o investimento repouse sobre o professor, uma vez que tanto a informação quanto a dimensão interativa são assumidas pelos produtores dos instrumentos (2000, p. 139).

Nesse cenário, as tecnologias contribuem com um contexto de desenvolvimento da qualidade e diversidade das práticas pedagógicas e das formas de aprender. Além de inserir os sujeitos em contato com a cultura midiática, que permite e possibilita o conhecimento e interação com diferentes culturas, conhecimentos e sujeitos, contribuindo assim com o processo de (re)conhecimento, respeito e valorização da diversidade.

No contexto de utilização da televisão é necessário relacionar no universo do aluno o abstrato com o concreto, partindo do conhecimento que o mesmo já possuí para construir, a partir das leituras em sala de aula, novos conhecimentos.

Com a era da informação, a cultura informacional suscita uma mudança no processo de interação entre sujeitos, em que a tecnologia media essas relações e contribui para que o 
sujeito construa conhecimentos em sua individualidade e, não necessariamente, no mesmo tempo e espaço, contribuindo assim para a construção da sociabilidade.

Sendo assim a televisão é considerada um meio de entretenimento, mas também de repasse de informações, e cabe a escola selecionar os conteúdos a serem trabalhados por esse recurso com os alunos, objetivando a construção de novos conhecimentos.

Como salienta Cardoso:

A existência de abundância de informação não constitui uma garantia de sua utilidade social, pois deve-se possuir os conhecimentos necessários para agir como filtro de informação, saber distinguir e selecionar, ou o acesso a toda essa informação será inútil (2007, p. 43).

$\mathrm{Na}$ escola, o docente é o mediador do conhecimento, portanto, ele deve realizar com criticidade a seleção dos conteúdos abordados em sala de aula, de forma que contribua com a criatividade, socialização, autonomia e o letramento dos alunos.

Como já salientado anteriormente, a televisão é um recurso tecnológico que muito contribui com o processo de ensino e de aprendizagem, mas para que ocorra de fato essas contribuições, faz-se necessário selecionar com conhecimento e criticidade os conteúdos a serem trabalhados com esse recurso audiovisual.

Muitos dos comportamentos dos alunos são copiados dos recursos audiovisuais que fazem parte da sua rotina abstrata (desenhos e filmes); logo, cabe aos docentes ensiná-los a compreenderem as falas, mensagens e imagens passadas pela televisão, levando os mesmos a entenderem o que é o universo abstrato e o que é a realidade, visto que, a educação busca desenvolver de forma integral os aspectos físicos, intelectuais, sociais e psicológicos dos sujeitos.

Deste modo, conhecer a realidade dos alunos, suas habilidades e dificuldades, permite ao docente maiores possibilidades de seleção dos recursos a serem utilizados em sala de aula, que irão contribuir com o aprendizado sem negar os conhecimentos que os discentes já possuem, articulando assim, de forma qualitativa, os recursos com o aprendizado.

Isto posto, o planejamento é fundamental para o alcance dos objetivos traçados pelo professor, na perspectiva de proporcionar um ensino contextualizado, socializador, crítico e desvelador das contradições sociais, com vistas a reforçar as desigualdades socioeconômicas, culturais e históricas existentes em nosso país, posto que, "O planejamento escolar é uma tarefa docente que inclui tanto a previsão das atividades didáticas em termos da sua organização e coordenação em face dos objetivos propostos, quanto a sua revisão e adequação no decorrer do processo de ensino" (LIBÂNEO, 2013, p. 245). 
Assim, é muito importante "[...] a atitude, o comportamento do professor que se coloca como um facilitador, incentivador ou motivador da aprendizagem que se apresenta com a disposição de ser uma ponte entre o aprendiz e sua aprendizagem [...]" (MASETTO, 2000, p. 144). A boa relação entre docente/discente e discente/docente é essencial para o processo de ensino e de aprendizagem de forma qualitativa, contribuindo com a construção de novos conhecimentos para ambos.

Ressalta-se que os alunos são produtores de história e serão protagonistas de suas vivências se forem autônomos, reflexivos e ativos. Segundo Kramer (1986), em suas relações sociais e culturais possuem valor; não são, somente, ocupantes de um espaço geográfico.

Para Ferréz (1996, p. 66), “[...] a linguagem audiovisual exercita atitudes perceptivas múltiplas, provoca constantemente a imaginação e confere à afetividade um papel de mediação primordial no mundo". Oferecendo assim momentos de aprendizados mais criativos, coletivos, expressivos, lúdicos e contextualizados com a realidade dos alunos.

Os filmes, desenhos, imagens, documentários e músicas não podem ter objetivos apenas ilustrativos, mas críticos e reflexivos, e devem ser mediados pelo professor, de forma que contribua com a escolarização e formação social dos discentes. Assim, o desafio dos docentes com o uso dos recursos tecnológicos é inserir as mídias nos objetivos educacionais despertando, assim, o interesse dos alunos pelo ensino. De acordo com Demo (2011, p. 22), "Para podermos influenciar positivamente nossos estudantes, é indispensável saber acompanhar as novas tecnologias e lidar com elas produtivamente".

A televisão por si só não contribui com a construção de novos conhecimentos; é necessária uma pedagogia reflexiva sobre o que foi trabalhado. A utilização da televisão de forma sempre livre e sem objetivos pedagógicos serve como veículo informativo e não possibilita a construção de conhecimentos.

Deste modo, a construção de novos conhecimentos, a socialização, a comunicação e interação no processo de ensino e de aprendizagem ocorre com a mediação docente em ensinar os alunos a refletirem sobre o que é apresentado dos conteúdos, fazendo uso da televisão. Logo, os recursos tecnológicos devem contribuir com a qualidade social da educação, democratização do conhecimento e a apreensão do contexto socioeconômico, cultural e político vivenciados.

\section{CONSIDERAÇÕES FINAIS}

O estudo realizado permitiu a compreensão de que o uso da televisão, como recurso pedagógico na sociedade atual, é relevante e necessário para a construção de um conhecimento ainda mais 
horizontalizado. Não obstante, a utilização desse recurso exige planejamento adequado aos objetivos propostos no plano de ensino pelo professor.

Nesse sentido, a mediação docente faz a diferença no uso das tecnologias digitais em sala de aula, uma vez que cabe ao educador suscitar a reflexão dos educandos quanto aos conteúdos trabalhados por meio das mensagens, ilustrações, filmes, documentários e músicas. Para essa mediação, o educador necessita de formação continuada quanto ao uso da tecnologia como recurso pedagógico, visto que a busca do conhecimento deve ser constante e precisa ser atualizada.

Salienta-se que a informação representa um rico componente na organização social e os fluxos de mensagens e imagens entre as redes sociais constituem a base da estrutura social. Logo, o novo paradigma da tecnologia da informação fornece a base material para a expansão, bem como, para a apreensão da rede social em toda a estrutura educacional.

Portanto, o uso dos recursos midiáticos já é uma realidade vivenciada no ambiente escolar, e sua utilização de maneira criativa, crítica, contextualizada e adequada aos objetivos de ensino propostos, constitui-se um desafio a ser enfrentado e superado pelo educador em sua prática docente.

\section{REFERÊNCIAS}

AMARAL, Sueli A. Os multimeios, a biblioteca e o bibliotecário. Revista de Biblioteconomia de Brasília, v. 15, n. 1, p. 45-68, jan./jun., 1987.

BRASIL. Lei n. 9394/96. Lei de Diretrizes e Bases da Educação Nacional. Brasília, DF, 1996.

CATELLS, Manuel. A sociedade em rede. Tradução de Roneide Venancio Majer. 17. ed. São Paulo: Paz e Terra, 2016.

CARDOSO, Gustavo. A mídia na sociedade em rede. Rio de Janeiro: Editora FGV, 2007.

DEMO, Pedro. Olhar do educador e novas tecnologias. B. Téc. Senac: a R. Educ. Prof. Rio de Janeiro, v. 37, n. 2, maio/ago., p. 15-26, 2011.

FERRÉZ, Joan. Vídeo e educação. In.: O uso didático do vídeo - modalidades. Porto Alegre: Arte Libâneo Médicas, 1996, p. 20-30.

KENSKI, Vani M. Tecnologias e ensino presencial e a distância. 9. ed. Campinas: Papirus, 2010. 
KRAMER, Sônia. O papel social da pré-escola. São Paulo: Fundação Carlos Chagas, 1986. (Cadernos de Pesquisa, 58).

LIBÂNEO, José Carlos. Adeus professor, adeus professora? Novas exigências educacionais e profissão docente. São Paulo: Cortez, 2011 (Coleção questões de nossa época).

LIBÂNEO, José Carlos. Didática. 2. ed. São Paulo: Cortez, 2013.

MASETTO, Marcos T. Mediação pedagógica e o uso da tecnologia. In MORAN, José Manuel; MASETTO, Marcos T.; BEHRENS Marilda Aparecida. Novas tecnologias e mediação pedagógica. Campinas: Papirus, 2000, p.133-173.

NAPOLITANO, Marcos. Como usar a televisão em sala de aula. São Paulo: Contexto, 2003.

PERRENOUD, Philippe. Dez novas competências para ensinar. Tradução de Patrícia Chittoni Ramos. Porto Alegre: Artmed, 2000.

PRETTO, Nelson de Luca. Uma escola sem/com futuro: educação e multimídia. São Paulo: Papirus, 1996.

SANTOS, Akiko. Didática sob a ótica do pensamento complexo. Porto Alegre: Sulina, 2004.

SOARES, Ismar de O. Educomunicação: o conceito, o profissional, a aplicação contribuições para o ensino médio. São Paulo: Paulinas, 2011.

\footnotetext{
* Doutoranda em Educação pela Universidade Federal da Grande Dourados (UFGD). Membro do Grupo de Pesquisa História da Educação, Memória e Sociedade (GEPHEMES/UFGD). E-mail: cristiapereira@hotmail.com Orcid: https://orcid.org/0000-0002-5906-2834

** Doutoranda em Educação pela Universidade Federal da Grande Dourados (UFGD). Professora coordenadora efetiva na Rede Municipal de Educação de Dourados-MS. Membro do grupo de pesquisa Estado, Política e Gestão da Educação (GEPGE/UFGD). E-mail: ma_3150@hotmail.com Orcid: https://orcid.org/0000-0002-9233-0204

*** Doutor em Letras pela Universidade de Brasília (UnB). Docente na Universidade Estadual de Mato Grosso do Sul (UEMS). E-mail: cleber101578@gmail.com Orcid: http://orcid.org/00000003-4463-6900
} 